\title{
Bacillus cereus Response to a Proanthocyanidin Trimer, a Transcriptional and Functional Analysis
}

\author{
Tomoko Tamura $^{1} \cdot$ Megumi Ozawa $^{2} \cdot$ Naoto Tanaka $^{3} \cdot$ Soichi Arai ${ }^{4} \cdot$ \\ Kiyoshi Mura ${ }^{1}$
}

Received: 28 August 2015/ Accepted: 21 February 2016/Published online: 9 April 2016

(C) The Author(s) 2016. This article is published with open access at Springerlink.com

\begin{abstract}
Proanthocyanidins are abundant in peanut skin, and in this study, the antibacterial effects of a peanut skin extract (PSE) against food-borne bacteria were investigated to find its minimum inhibitory concentration. Food-borne gram-positive bacteria, and in particular Bacillus cereus, was more sensitive to PSE. In particular, the inhibitory activity of epicatechin- $(4 \beta \rightarrow 6)$-epicatechin- $(2 \beta \rightarrow \mathrm{O} \rightarrow 7, \quad 4 \beta \rightarrow 8)$ catechin (EEC), a proanthocyanidin trimer from peanut skin, against $B$. cereus was stronger than that of procyanidin $\mathrm{A} 1$, a proanthocyanidin dimer. DNA microarray analysis of $B$. cereus treated with EEC was carried out, with a finding that 597 genes were significantly up-regulated. Analysis of the up-regulated genes suggested that EEC disrupted the normal condition of the cell membrane and wall of $B$. cereus and alter its usual nutritional metabolism. Moreover, treatment of B. cereus with EEC inhibited glucose uptake, suggesting that EEC affects the cell-surface adsorption.
\end{abstract}

Electronic supplementary material The online version of this article (doi:10.1007/s00284-016-1032-x) contains supplementary material, which is available to authorized users.

Tomoko Tamura

t3tamura@nodai.ac.jp

1 Department of Nutritional Science and Food Safety, Faculty of Applied Bioscience, Tokyo University of Agriculture, 1-1-1 Sakuragaoka, Setagaya-ku, Tokyo 156-8502, Japan

2 Advantec.Co., Ltd, 2-7-1 Nishisinjuku, Sinjuku-ku, Tokyo 163-0703, Japan

3 Faculty of Applied Bioscience, Nodai Culture Collection Center, Tokyo University of Agriculture, 1-1-1 Sakuragaoka, Setagaya-ku, Tokyo 156-8502, Japan

4 Nodai Research Institute, Tokyo University of Agriculture, 1-1-1 Sakuragaoka, Setagaya-ku, Tokyo 156-8502, Japan

\author{
Abbreviations \\ COG Clusters of orthologous groups \\ EEC Epicatechin- $(4 \beta \rightarrow 6)$-epicatechin- $(2 \beta \rightarrow \mathrm{O} \rightarrow 7$, \\ $4 \beta \rightarrow 8)$-catechin \\ MIC Minimum inhibitory concentration \\ NRIC NODAI Culture Collection Center \\ PBP Penicillin-binding proteins \\ PSE Peanut skin extract \\ TCS Two-component signal transduction system
}

\section{Introduction}

Bacillus cereus is a gram-positive food-borne bacterium, and is widely distributed in the environment, mainly in soil. Thus, foods such as carrot, zucchini, rice, eggs, and milk are a potential risk for B. cereus contamination. B. cereus are able to withstand low $\mathrm{pH}$ conditions such as foods acidified during food processing and conservation. Moreover, B. cereus spores are resistant to gastric acidity [4]. Therefore chemical and physical treatments including hydrogen peroxide, $\mathrm{NaClO}$, ozone, and $\mathrm{UV}$ light have been used to inactivate B. cereus [12].

Recently, it was demonstrated that plant metaboites like polyphenols possess antimicrobial activities [9]. Tea catechins are well-known plant polyphenols and have antimicrobial activities against $B$. cereus $[9,10]$. Friedman et al. [9] reported that epigallocatechin gallate, epicatechin-3gallate, and theaflavin gallate show antimicrobial activities at nanomolar levels, while tea catechins without gallate side chains, $( \pm)$-catechin and gallic acid, are all inactive. Accordingly, the authors suggested that the antimicrobial effect of catechins is strongly influenced by their structure. 
Besides tea catechins, phenolic compounds in cinnamon, olive oil, and strawberry grapes have also been shown to have antimicrobial properties [3, 11, 16]. Although the antimicrobial capacity of phenolic compounds has been studied at the structural and stereochemical levels, little information is available about the physiological responses of bacteria upon exposure to polyphenols.

The red skin of the peanut (Arachis hypogaea L.) contains high levels of polyphenols. We have previously demonstrated the antiallergic, hypocholesterolemic, hypoglycemic, and antioxidative effects of peanut skin polyphenols [7, 18, 20, 21]. We also identified procyanidin A1 as a proanthocyanidin dimer and epicatechin- $(4 \beta \rightarrow 6)$ epicatechin- $(2 \beta \rightarrow \mathrm{O} \rightarrow 7,4 \beta \rightarrow 8)$-catechin (EEC) as a proanthocyanidin trimer from peanut skin (Fig. 1a). EEC exhibited a more potent cholesterol micelle-degrading activity compared to procyanidin A1, while (+)-catechin had no activity [18]. In addition, the inhibitory effects on

\section{a}

epicatechin-( $4 b \rightarrow 6)$-epicatechin- $(2 b \rightarrow O \rightarrow 7,4 b \rightarrow 8)$-catechin (EEC)
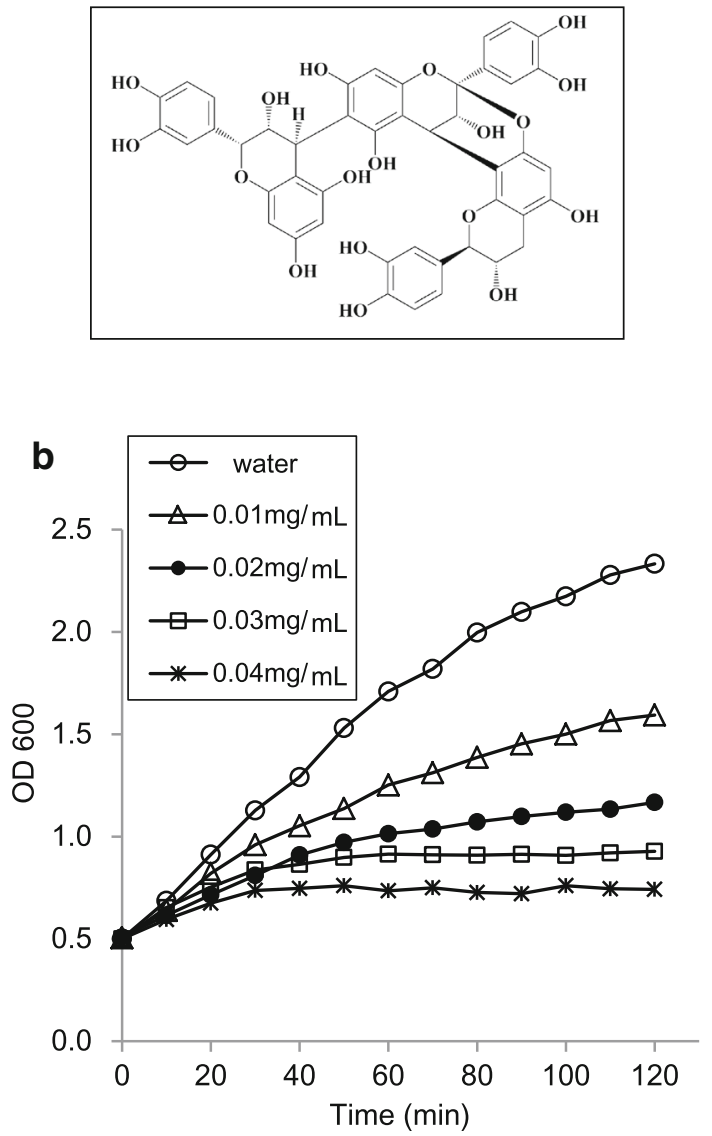

Fig. 1 Structure of EEC (a) and growth curves of B. cereus ATCC 14579 in the presence of different concentrations of EEC (b). $B$. cereus was grown in $\mathrm{LB}$ medium to an $\mathrm{OD}_{600}$ of 0.5 and treated with different concentrations of EEC for $120 \mathrm{~min}$ sugar digestion enzymes and glucose transport were increased as the degree of polymerization increased [20], and EEC in particular exerted highly hypocholesterolemic and hypoglycemic effects.

Therefore, we assessed the antimicrobial mechanisms of peanut skin polyphenols, particularly EEC. The main goal of this study was to determine the antimicrobial activity of peanut skin polyphenols and to investigate the responses of B. cereus in the EEC stress condition using gene expression analysis. In this study, three types of experiments were conducted. First, we compared the activity of peanut skin polyphenols against many bacterial species to clarify their antibacterial spectrum. Next, we performed DNA microarray for genome-wide transcriptional analysis of $B$. cereus ATCC 14,579 in the presence of EEC, and finally, we confirmed the response of $B$. cereus to EEC treatment by quantitative real-time PCR and glucose uptake test.

\section{Materials and Methods}

\section{Peanut Skin Polyphenol Extraction}

Peanut skin extract (PSE) was obtained from peanut skin as previously reported [18]. In brief, peanut skins were boiled in water for $30 \mathrm{~min}$, and precipitate was separated from the supernatant and boiled again in water. This was repeated 5 times, and all supernatants were concentrated in vacuo to obtain PSE. Higher- and lower-molecular weight fractions were prepared by ultrafiltration (MWCO 10,000; Advantec, Tokyo). Procyanidin A1 and EEC were separated by chromatography on a TSK-gel Toyopearl HW-40 F column $(26 \times 800 \mathrm{~mm})($ Tosoh Bioscience, Tokyo), and YMC-gel ODS-AQ 12S50 column (YMC, Kyoto), as described previously $[18,21]$. Total polyphenol content was determined according to the method of Singleton and Rossi [17] with Folin-Ciocalteu's reagent.

\section{Microbial Strains}

The following strains were used as indicators for the antibacterial testing and were obtained from the NODAI Culture Collection Center (NRIC): Bacillus cereus NRIC 0591 (=ATCC14579), Bacillus subtilis NRIC 0546 (=168), Clostridium butyricum NRIC 0221, Lactobacillus plantarum NRIC 1062 (=NBRC 3074), Micrococcus luteus NRIC 1094 (=ATCC 4698), Staphylococcus aureus NRIC 1135 (=ATCC 11,522), Streptococcus mutans NRIC 0528, Streptococcus sobrinus NRIC 1694, Escherichia coli NRIC 1023 (=NBRC 3301), Salmonella enterica subsp. enterica serovar Typhimurium NRIC 0820 (=NBRC 13245), Vibrio fluvialis NRIC 0818 (=JCM 3752), Vibrio vulnificus NRIC 0817 (=JCM 3725), Vibrio parahaemolyticus NRIC 0821 
(=NBRC 12711), Yersinia enterocolitica subsp. enterocolitica NRIC 0819 (=JCM 7577).

\section{Antibacterial Activity Test}

Twenty milliliters of the test cultivation medium (Online Resource 1) was applied to a petri dish $(90 \mathrm{~mm}$ in diameter). After preculture of bacteria in each medium (Online Resource 1), $0.3 \mathrm{~mL}$ of the bacterial suspension was added to $4 \mathrm{~mL}$ of test cultivation medium before agar has solidified prior to layering on the test cultivation medium. Next, a cylinder $(6 \times 8 \mathrm{~mm})$ was placed on the dish and different concentrations of $0.2 \mathrm{~mL}$ of PSE, procyanidin A1 or EEC were poured into the cylinder. The antibacterial activity test was carried out in test cultivation medium (Nissui, Tokyo, Japan) at 25 or $37{ }^{\circ} \mathrm{C}$ (Online Resource 1) for one day, or for two days for Streptococcus mutans, Streptococcus sobrinus, and Yersinia enterocolitica subsp. Enterocolitica, or 10 days for Clostridium butyricum. The minimum inhibitory concentration (MIC) and the value for each polyphenol or extract against each bacterium was determined from three independent experiments.

\section{Growth Curves of B. Cereus in the Presence of EEC}

In liquid culture experiments, $20 \mathrm{~mL}$ of LB medium was inoculated with $0.1 \%(\mathrm{v} / \mathrm{v})$ of overnight culture. When the OD of the bacterial culture at $600 \mathrm{~nm}$ reached 0.5 , procyanidin A1 or EEC was added to the culture. After the addition of procyanidin $\mathrm{A} 1$ or $\mathrm{EEC}$, the $\mathrm{OD}_{600}$ was measured at 10 min intervals.

\section{Microarray Design}

The microarray used in this study was custom made for $B$. cereus using standard Agilent Technologies protocols (https://earray.chem.agilent.com/earray/). The B. cereus microarray design was based on the 5234 predicted open reading frames available at NCBI (Accession No. AE016877). Three non-overlapping probes were designed per gene and a final 15242 probes were spotted per array.

\section{Total RNA Isolation}

When the B. cereus culture reached an $\mathrm{OD}_{600}$ of 0.5 , samples for RNA isolation were taken before addition of $0.02 \mathrm{mg} / \mathrm{mL}$ EEC and after $30 \mathrm{~min}$ of exposure to EEC. Water was added in place of EEC as a control. RNA isolation, DNA removal with DNase I, and RNA purification were done using a Qiagen RNeasy kit according to the manufacturer's instructions (Qiagen, Tokyo). RNA quality and quantity were determined as described previously [19].

\section{cDNA Labeling and Microarray Hybridization}

The cDNA labeling and microarray hybridization were performed using FairPlay Microarray Labeling kit and Gene Expression Hybridization Kit (Agilent Technologies, Palo Alto, CA). The B. cereus microarrays were hybridized (http://www.ncbi.nlm.nih.gov/geo/query/acc.cgi?acc=GSE6 8767), and scanned after washing in an Agilent microarray scanner (G2565CA).

\section{Analysis of Microarray Data}

Analysis of the scanned images was performed as described previously. In brief, data were normalized to 75 th percentile and the difference was found to be significant by unpaired $T$-test $(P=0.05)$. Changes in expression greater than 2-fold, for up-regulated genes, and greater than 0.5fold, for down-regulated genes were regarded as biologically significant. The genes were then divided into classes based on the Clusters of orthologous groups of proteins (COG) classification.

\section{Quantitative Real-Time PCR Analysis}

One microgram of total RNA (3 independent samples/ treatment) was used as a template for first-strand cDNA synthesis using a First-Strand cDNA Synthesis Kit (QuantiTect Reverse Transcription Kit). Quantitative real-time PCR was performed as described previously [19] using the following primer sets: GTP pyrophosphokinase, 5'- TCGC TAACCCAAAACGAAAC $-3^{\prime}$ and $5^{\prime}$ - TGCCCAAAAGT CCATTGC -3', GenBank Accession No. BC_4341; lia operon protein Lial homologous gene, 5'- CGGAGCAGG AGTTGTATATTGG $-3^{\prime}$ and $5^{\prime}$ - GCTGGCGAATGAG AAAGTG -3', BC_1435; Phage shock protein A, 5'- TGG CACATGCAAATCGTC $-3^{\prime}$ and 5'- CACGCTCATG CTCTTCATTC -3', BC_1436; Penicillin-binding proteins $(P B P)$ 1A, $5^{\prime}$ - CGTTAGATCCGAAAGCACAG $-3^{\prime}$ and $5^{\prime}-$ ATTTTCTCCACGGCCACTAC -3', BC_2281; 165 ribosomal RNA, $5^{\prime}$ - TGGGGAGCAAACAGGATTAG $-3^{\prime}$ and 5'- CCTTTGAGTTTCAGCCTTGC - ${ }^{\prime}$, BC_0007. The amount of gene expression was normalized with the level of $16 \mathrm{~S}$ ribosomal RNA expression. The relative amounts of gene expression were calculated using the standard curve method, and expressed relative to the control. Differences among all conditions were detected by Tukey's multiple-range test following a one-way analysis of variance (ANOVA). Statistical analyses were performed with SPSS software. 


\section{Glucose Uptake Assays}

Cells were grown in $\mathrm{LB}$ medium until the $\mathrm{OD}_{600}$ was 0.5 , and EEC at a final concentration of $0.05 \mathrm{mg} / \mathrm{mL}$ was added. Water was added for control experiments. Measurement of D-glucose uptake was started by the addition of $1 \mathrm{mM}$ D-glucose containing $6.17 \mathrm{KBq} / \mathrm{mL}$ of $\left[{ }^{14} \mathrm{C}\right]$-D-glucose (Perkin Elmer, Inc., MA, USA). After incubation for 10,20 , and $30 \mathrm{~min}$ at $37{ }^{\circ} \mathrm{C}, 300 \mu \mathrm{L}$ aliquots were collected and the reaction was stopped by the addition of 750 $\mu \mathrm{L}$ of ice-cold LB medium containing $140 \mathrm{mM}$ glucose. The cells were collected by filtration through a $0.45-\mu \mathrm{m}$ pore size membrane filter (Millipore, Ireland), and the filters were then washed with $1 \mathrm{~mL}$ of $50 \mathrm{mM}$ ice-cold phosphate buffer (pH6.5). The filters were air-dried, and cell-associated radioactivity was measured in a scintillation counter. All assays were performed in triplicate. Statistical analyses were performed with SPSS software, and between-group differences were detected by T-test.

\section{Results}

\section{Antibacterial Spectrum of PSE}

Peanut skin presented a total of $126.3 \mathrm{mg}$ polyphenols, and $0.3 \mathrm{mg}(+)$-catechin, $7.1 \mathrm{mg}$ procyanidin $\mathrm{A} 1$, and $2.8 \mathrm{mg}$ EEC per g dry skin.

The susceptibility to PSE was significantly different for Gram-positive and Gram-negative bacteria (Table 1). Bacillus cereus and Clostridium butyricum (MIC, $0.25 \mathrm{mg} / \mathrm{mL}$ ) showed comparatively strong susceptibility. The MICs of PSE for Lactobacillus plantarum, Micrococcus luteus, Staphylococcus aureus are 7.84, 0.31, $1.16 \mathrm{mg} / \mathrm{mL}$, respectively, when chemically defined protein-free medium was used instead of sensitivity disk agar medium (data not shown). On the other hand, Gramnegative bacteria were not affected by PSE up to a concentration of $5.05 \mathrm{mg} / \mathrm{mL}$.

\section{Antibacterial Activity of EEC}

To investigate the overall changes in gene expression of $B$. cereus in response to EEC, cells should be treated with sublethal but growth-inhibitory concentrations. As reflected in the growth curves (Fig. 1b), $0.01 \mathrm{mg} / \mathrm{mL}$ of EEC inhibited the growth rate about two-fold. In the presence of $0.03 \mathrm{mg} / \mathrm{mL}$ EEC, the growth of $B$. cereus was completely inhibited. The effect of EEC concentration on $B$. cereus growth could be seen after $30 \mathrm{~min}$, and was prominent after 60 min. Procyanidin A1, a proanthocyanidin dimer (Online Resource 2), also possessed inhibitory activity towards $B$. cereus growth, but the antibacterial activity was 10 -fold less than that of EEC (Online Resource 2). Therefore, we carried out DNA microarray analysis on B. cereus after $30 \mathrm{~min}$ exposure to $0.02 \mathrm{mg} / \mathrm{mL}$ EEC.

\section{Numbers of Differentially Expressed Genes in Response to EEC}

Three conditions 8 samples were normalized to 75 th percentile and constructed a cluster dendrogram by pvclust function in statistical language R, version 2.14.0 (Fig. 2), with the result that the water treatment (control) and the EEC treatment belong to different clusters. Statistical analysis indicated that changes in the expression of 1055 genes, represented by 2181 probes, were significant. Among these genes, 596 were up-regulated and 495 were down-regulated. All the extracted genes by the transcriptomic analysis are shown in Online Resource 3.

Table 1 Minimum inhibitory concentration (MIC) of PSE

\begin{tabular}{llc}
\hline Group & Strain & MIC Polyphenol (mg/mL) \\
\hline Gram-positive bacteria & Bacillus cereus ATCC 14579 & 0.25 \\
& Bacillus subtilis 168 & 2.58 \\
& Clostridium butyricum NRIC 0221 & 0.25 \\
& Lactobacillus plantarum IFO 3074 & $>5.05$ \\
& Micrococcus luteus ATCC 4698 & $>5.05$ \\
& Staphylococcus aureus ATCC 11522 & $>5.05$ \\
Gram-negative bacteria & Streptococcus mutans NRIC 0528 & $>5.05$ \\
& Escherichia coli IFO 3301 & $>5.05$ \\
& Salmonella enterica subsp. Enterica serovar Typhimurium IFO 12529 & $>5.05$ \\
& Vibrio vulnificus JCM 3725 & $>5.05$ \\
& Vibrio parahaemolyticus NBRC 12711 & $>5.05$ \\
& Yersinia enterocolitica subsp. enterocolitica JCM 7577 & $>5.05$ \\
\hline
\end{tabular}




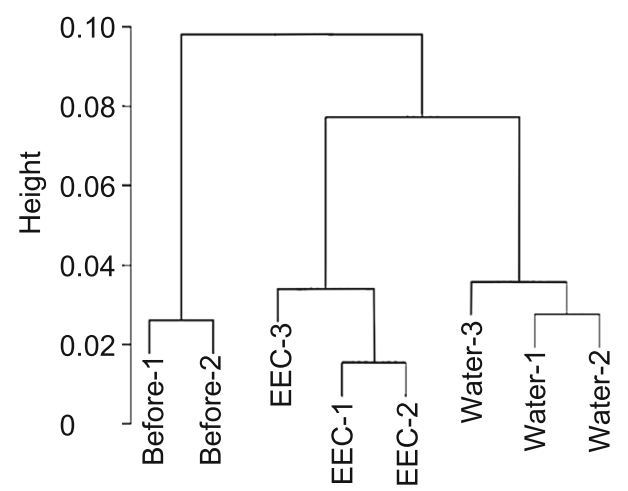

Fig. 2 Cluster dendrogram of genes expressed in B. cereus. Eight samples from three conditions were used to construct the dendrogram using the 'pvclust' function. Before, 0 min after the addition of EEC $\left(\mathrm{OD}_{600}=0.5\right)$ to the medium; EEC, $30 \mathrm{~min}$ after the addition of $0.02 \mathrm{mg} / \mathrm{mL}$ of EEC; Water, $30 \mathrm{~min}$ after the addition of water (control)

\section{COG Classification}

Figure 3 shows up- and down-regulated genes divided into classes based on the COG classification. Genes up-regulated by EEC treatment were enriched in genes involved with "lipid transport and metabolism" and "defense metabolism". Genes involved in "amino acid transport and metabolism", "coenzyme transport and metabolism", and "lipid transport and metabolism" were also up-regulated. Genes down-regulated by EEC treatment were enriched in genes involved in "nucleotide transport and metabolism". Genes related to "cell motility" and "energy production and conversion" were also down-regulated.

\section{Gene Expression Changes of B. Cereus ATCC14579 in Response to EEC}

Table 2 shows the top 50 genes up-regulated by EEC exposure. The most abundant functional category is ABC transporters and include two genes whose expression changed over $>6100$ fold and 11 more genes that increased $>11$ fold. The genes encoding GTP pyrophosphokinase that is related to stringent response, was also up-regulated. When analyzed by real-time PCR, the expression level of GTP pyrophosphokinase was increased 62.5-fold within 10 min by EEC (Fig. 1a) exposure, and maintained thereafter. (Figure 4a). Genes belonging to the two-component regulatory system, Lia I homologs and phage shock protein
Fig. 3 Differentially expressed genes $(P<0.05)$ in the presence of EEC on the basis of COG classification. Some genes belong to more than one category

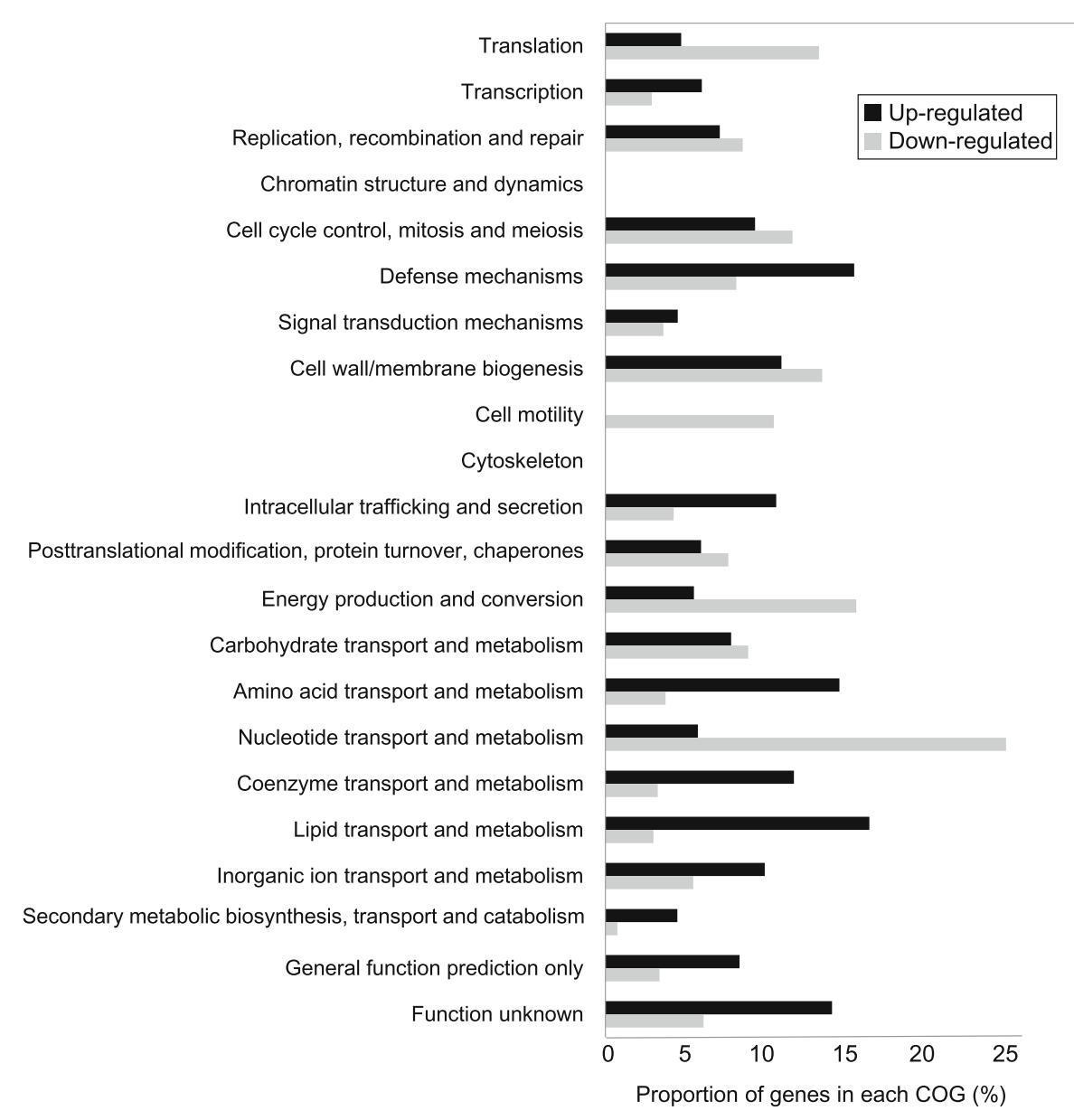


Table 2 Top 50 genes up-regulated by EEC exposure

\begin{tabular}{|c|c|c|c|}
\hline Locus tag & Fold Change & Description & Genes related to \\
\hline BC_5014 & 6557.9 & Hypothetical exported repetitive protein & $\mathrm{ABC}$ transporter \\
\hline BC_5015 & 6120.1 & Hypothetical exported repetitive protein & $\mathrm{ABC}$ transporter \\
\hline BC_0575 & 1470.2 & Hypothetical protein & \\
\hline BC_0574 & 519.0 & Hypothetical Membrane spanning protein & $\mathrm{ABC}$ transporter \\
\hline BC_2620 & 140.5 & Penicillin-binding protein transpeptidase & Polymerization of glycan \\
\hline BC_2985 & 70.4 & Vancomycin B-type resistance protein vanW & Polymerization of glycan \\
\hline BC_0572 & 59.3 & Two-component response regulator & Two-component regulatory system \\
\hline BC_0573 & 56.7 & Two-component system histidine kinase & Two-component regulatory system \\
\hline BC_2621 & 54.9 & Signal peptidase I & \\
\hline BC_1161 & 50.4 & Foldase protein prsA 2 & \\
\hline BC_2895 & 50.2 & Hypothetical protein & \\
\hline BC_1760 & 43.6 & 3-Oxoacyl-(acyl carrier protein) synthase III & \\
\hline BC_0754 & 33.5 & Potassium-transporting ATPase B chain & Two-component regulatory system \\
\hline BC_0755 & 26.9 & Potassium-transporting ATPase C chain & Two-component regulatory system \\
\hline BC_0785 & 23.8 & Hypothetical protein & \\
\hline BC_4341 & 23.1 & GTP pyrophosphokinase & Stringent response \\
\hline BC_2984 & 21.2 & Immune inhibitor A precursor & \\
\hline BC_1419 & 20.2 & Diaminopimelate decarboxylase & \\
\hline BC_4775 & 20.0 & Phosphoglycerol transferase & \\
\hline BC_4251 & 17.5 & $\begin{array}{l}\text { Bifunctional homocysteine S-methyltransferase/5,10- } \\
\text { methylenetetrahydrofolate reductase protein }\end{array}$ & \\
\hline BC_3410 & 17.4 & D-Threo-aldose 1-dehydrogenase & \\
\hline BC_2603 & 17.3 & Putative uncharacterized protein & \\
\hline BC_1461 & 16.5 & DNA integration/recombination/invertion protein & \\
\hline BC_1779 & 16.3 & Ketol-acid reductoisomerase & \\
\hline BC_2496 & 15.9 & D-Alanyl-D-alanine carboxypeptidase & Polymerization of glycan \\
\hline BC_0753 & 15.6 & Potassium-transporting ATPase subunit A & Two-component regulatory system \\
\hline BC_1394 & 15.3 & UPF0180 protein BC_1394 & \\
\hline BC_2169 & 15.2 & Aspartyl-tRNA synthetase & \\
\hline BC_1777 & 14.9 & Acetolactate synthase large subunit & \\
\hline BC_1825 & 14.4 & Transposase & \\
\hline BC_1435 & 14.4 & Hypothetical protein & Two-component regulatory system \\
\hline BC_4254 & 14.3 & Cystathionine beta-lyase & \\
\hline BC_3600 & 14.3 & Protease HhoA & \\
\hline BC_2323 & 14.1 & $\mathrm{ABC}$ transporter ATP-binding protein & $\mathrm{ABC}$ transporter \\
\hline BC_3199 & 14.1 & Hypothetical Cytosolic Protein & $\mathrm{ABC}$ transporter \\
\hline BC_1781 & 14.0 & Threonine dehydratase & \\
\hline BC_4667 & 13.8 & Ankyrin & \\
\hline BC_4742 & 13.8 & $\mathrm{ABC}$ transporter permease protein & $\mathrm{ABC}$ transporter \\
\hline BC_0347 & 13.5 & $\mathrm{ABC}$ transporter permease protein & $\mathrm{ABC}$ transporter \\
\hline BC_4830 & 13.4 & $\mathrm{ABC}$ transporter permease protein & $\mathrm{ABC}$ transporter \\
\hline BC_4831 & 13.2 & $\mathrm{ABC}$ transporter ATP-binding protein & $\mathrm{ABC}$ transporter \\
\hline BC_2977 & 12.6 & Pyrroline-5-carboxylate reductase & \\
\hline BC_1995 & 12.4 & $\mathrm{ABC}$ transporter permease protein & $\mathrm{ABC}$ transporter \\
\hline BC_4545 & 12.3 & Ferrichrome transport system permease protein fhuB & $\mathrm{ABC}$ transporter \\
\hline BC_4743 & 12.3 & $\mathrm{ABC}$ transporter ATP-binding protein & $\mathrm{ABC}$ transporter \\
\hline BC_4038 & 12.0 & Methylthioribulose-1-phosphate dehydratase & \\
\hline BC_0816 & 11.9 & Periplasmic component of efflux system & \\
\hline
\end{tabular}


Table 2 continued

\begin{tabular}{lcll}
\hline Locus tag & Fold Change & Description & Genes related to \\
\hline BC_4134 & 11.8 & pyrroline-5-carboxylate reductase & ABC transporter \\
BC_0814 & 11.7 & ABC transporter permease protein & \\
BC_2272 & 11.5 & Peptidylprolyl isomerase & \\
\hline
\end{tabular}

Fig. 4 Time-course changes in gene expression in B. cereus after EEC exposure. The relative amounts of GTP pyrophosphokinase (a), LiaI homologous gene (b), phage shock protein $\mathrm{A}(\mathbf{c})$, and PBP1A (d) were normalized with the level of $16 \mathrm{~S}$ ribosomal RNA expression, and were calculated relative to expression at $0 \mathrm{~min}$. Error bars indicate standard deviation $(n=3)$. Different letters are significantly different at $(p<0.05)$ according to Tukey's multiple-range test among all conditions
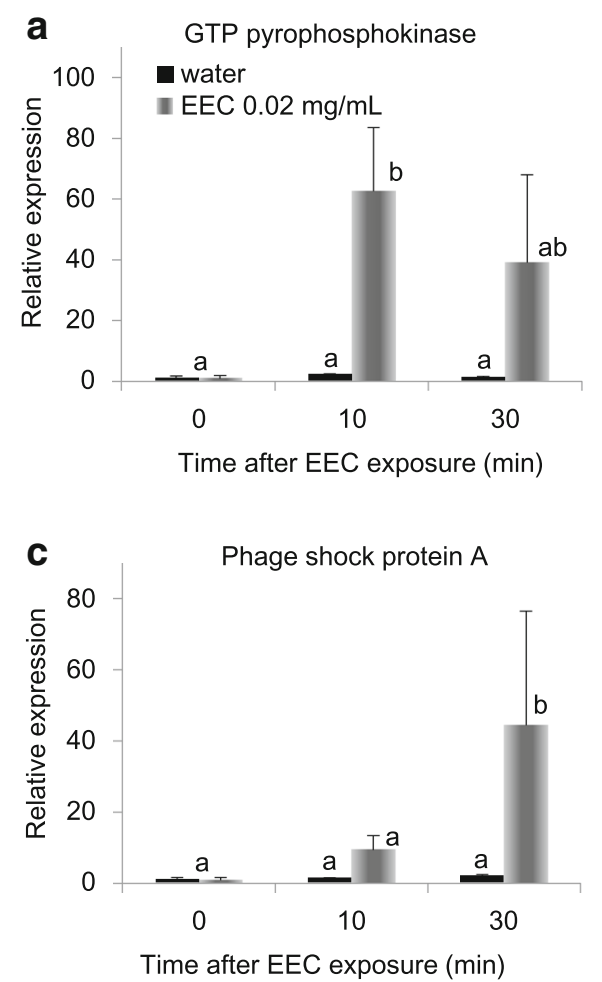
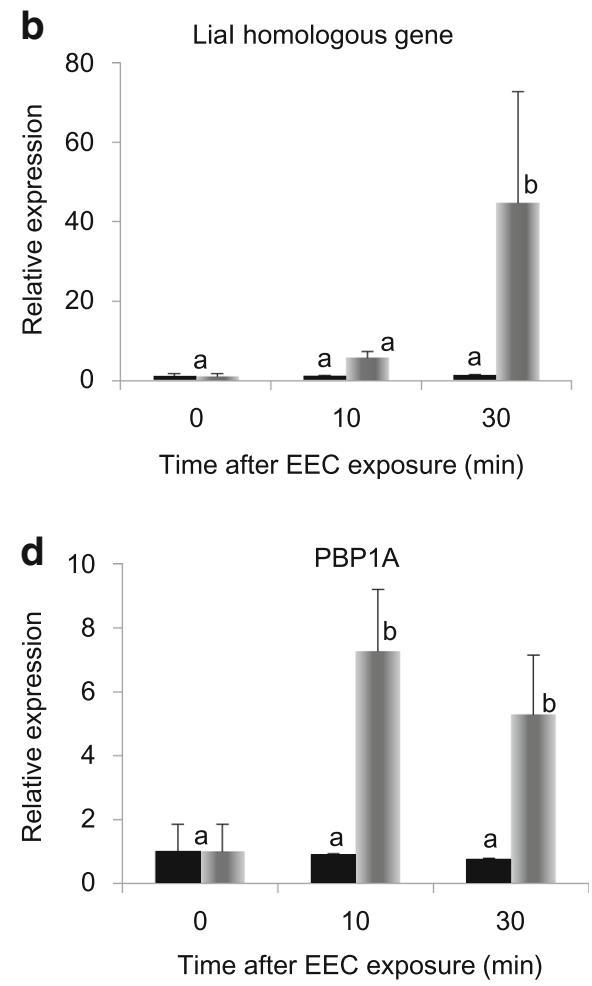

$A$, were also up-regulated by EEC treatment. Their expression increased 5.7- and 9.5-fold, respectively, $10 \mathrm{~min}$ after EEC exposure, and further increased after $30 \mathrm{~min}$ of exposure, to 44.7- and 44.5-fold, respectively (Fig. 4b, c). Of the genes related to further polymerization of glycin, PBPIA was also prominently increased, and realtime PCR showed a 7.3-fold increase within $10 \mathrm{~min}$ and a 5.3-fold increase after $30 \mathrm{~min}$ of exposure to EEC (Fig. 4d). The expression changes of three genes encoding bacillibactin synthesis enzymes, 2,3-dihydroxybenzoateAMP ligase, isochorismatase, and glycine-AMP ligase are also measured and were significantly increased after $10 \mathrm{~min}$ of EEC exposure, and then reduced $30 \mathrm{~min}$ after treatment (Online Resource 4).

\section{Inhibitory Effect of EEC on Glucose Uptake}

To further examine the effect of EEC on nutritional metabolism, we studied glucose uptake. Figure 5 shows the level of glucose uptake in B. cereus after EEC exposure.
The glucose uptake level was significantly decreased after $30 \mathrm{~min}$ incubation with $0.05 \mathrm{mg} / \mathrm{mL}$ of EEC, although no difference was observed after $10 \mathrm{~min}$ incubation. There was no difference in glucose uptake between the control and EEC when used at $0.02 \mathrm{mg} / \mathrm{mL}$ EEC, the concentration used for DNA microarray analysis (data not shown).

\section{Discussion}

The antibacterial spectrum of PSE showed that the inhibitory effect of PSE was more effective against Grampositive than Gram-negative bacteria (Table 1). We hypothesize that the PSE may more easily access the cell membrane and the cell wall of gram-positive bacteria. More than $5.05 \mathrm{mg} / \mathrm{mL}$ PSE might inhibit the growth of gram-negative bacteria including $E$. coli, but results were not obtained, because osmotic pressure had been produced between solid medium and PSE solution, and hence water filled the inside of the cylinder. On the other hand, less than 


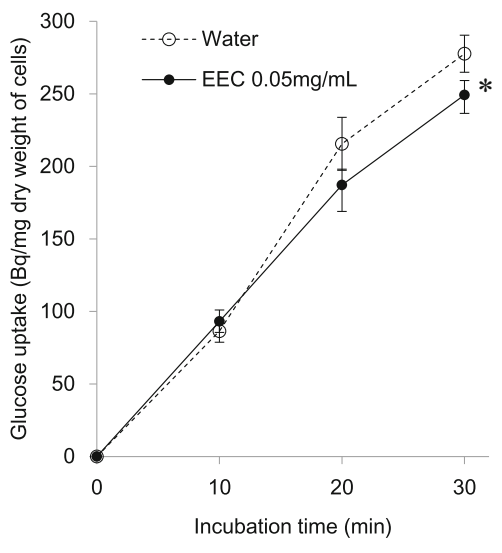

Fig. 5 Effect of EEC on glucose uptake by B. cereus. B. cereus was grown in $\mathrm{LB}$ medium to an $\mathrm{OD}_{600}$ of 0.5 , and $0.05 \mathrm{mg} / \mathrm{mL}$ of EEC, and $1 \mathrm{mM}$ D-glucose containing $6.17 \mathrm{KBq} / \mathrm{mL}$ of $\left[{ }^{14} \mathrm{C}\right]-\mathrm{D}-$ glucose were added to the medium. After incubation for 10, 20, and $30 \mathrm{~min}$ at $37{ }^{\circ} \mathrm{C}$, the reaction was stopped, and cells were collected by filtration. The filters were air-dried, and cell-associated radioactivity was measured in a scintillation counter. Error bars indicate standard deviation $(n=3)$. Asterisk indicates significant difference at $P<0.05$

$5.05 \mathrm{mg} / \mathrm{mL}$ PSE were enough to inhibit growth of Lactobacillus plantarum, Micrococcus luteus, and Staphylococcus aureus when chemically defined protein-free medium was used. We expected that components of medium could affect the sensitivity to PSE in Gram-positive bacteria. EEC inhibited the growth of B. cereus to a greater extent than procyanidin A1 (Online Resource 2). Although Verstraeten et al. [22] reported that proanthocyanidin dimers and trimers from cacao and peanut skin can interact with membrane phospholipids and decrease membrane fluidity to a similar degree, we suggest EEC, the proantocyanidin trimer, exerts stronger antibacterial activity than procyanidin $\mathrm{A} 1$, a proantocyanidin dimer.

Exposure of B. cereus to EEC altered the expression of genes related to stringent response, which aids in survival during nutrient limitation. Bacteria respond to nutritional starvation by producing guanosine $5^{\prime}$-diphosphate (or $5^{\prime}$ triphosphate) $3^{\prime}$-diphosphate (ppGpp) in the cell $[14,15]$. This compound regulates the activities of various enzymes that mediate nucleotide metabolism, transcription, translation, and DNA replication [24]. Synthesis of ppGpp is mediated by GTP pyrophosphokinase using ATP and GDP(GTP) and its hydrolysis to GDP(GTP) and pyrophosphate. In this study, the gene encoding GTP pyrophosphokinase was induced by EEC exposure (Fig. 4a), suggesting that ppGpp would regulate amino acid, lipid, coenzyme, and nucleotide metabolism and translation (Fig. 3).

The gram-positive cell envelope consists of two functional layers (compared with three in gram-negative bacteria): a cytoplasmic membrane surrounded by a thick cell wall [2]. EEC also affected the expression of the twocomponent signal transduction system (TCS). Bacteria possess the LiaSR system of the TCS, which responds to cell wall antibiotics, and interferes with perturbation of the cytoplasmic membrane [13]. The primary target gene of LiaSR is liaIH, and its physiological role is largely unknown, though Lia $\mathrm{H}$ is a member of the phage shock protein family [13]. Recently, several mechanisms were proposed to explain the antimicrobial activity of the A-type proanthocyanidin, such as the destabilization of the cytoplasmic membrane and the permeabilization of the cell membrane [5, 6]. Bernal et al. [1] provided evidence that epicatechin gallate binds to the cytoplasmic membrane of methicillin-resistant Staphylococcus aureus and penetrates deep into the hydrophobic region of the bilayer. As a result, $\mathrm{ECg}$ reduces membrane fluidity and disrupts cell wall synthesis. In this study, expression of LiaI homologous genes and phage shock protein were slightly increased after $10 \mathrm{~min}$ of EEC exposure, but significantly increased after $30 \mathrm{~min}$ (Fig. 4b, c). Genes related to polymerization of glycan were also increased by EEC exposure. The polymerization and cross-linking of peptidoglycan is mediated by PBPs. RT-PCR analysis revealed that PBP1A, was increased 10 min after EEC administration (Fig. 4d). We suggest that EEC may disrupt the normal condition of the cell membrane and the cell wall of $B$. cereus. It can be presumed that the destabilization of the cytoplasmic membrane would affect the membrane-associated enzymes and certain intracellular transport mechanisms. Thus, we tested the influence of EEC on glucose uptake by $B$ cereus, and predictably, EEC blocked the glucose transporter or affected the transmembrane condition, and reduced the level of glucose uptake (Fig. 5).

It is known that one of the mechanisms of bacterial growth inhibition is deprivation of essential mineral micronutrients, such as iron and zinc, via proanthocyanidin chelation with metals [5, 6]. Many bacteria secrete siderophores [23], low molecular weight carriers with high affinity for $\mathrm{Fe}^{3+}$ to grow in iron-deficient substrates. Although Engels et al. [8] demonstrated that the inhibitory activities of gallotannins are attributable to their strong affinity for iron, and likely relate to the inactivation of membrane-bound proteins, our results suggest that iron deprivation would not be directly responsible to the antimicrobial activity of EEC against $B$. cereus.

Collectively, our results suggest that the peanut skin is a potential source of antibacterial agents with bacteriostatic activity against $B$. cereus. EEC could be keeping B. cereus at low levels cause the disruption of normal conditions in the cell membrane and the cell wall and affect the function of membrane-binding protein. Additional genetic and biochemical analysis of B. cereus about toxin production and spore formation will be needed to elucidate the 
bacteriostatic activity of EEC. It is also important to analyze the effectiveness of EEC when $B$. cereus is in a food commodity.

Acknowledgments This work was supported by a Grant-in-Aid for Young Scientist (B) No. 26750027 from the Japan Society for Promotion of Science (JSPS).

Open Access This article is distributed under the terms of the Creative Commons Attribution 4.0 International License (http://crea tivecommons.org/licenses/by/4.0/), which permits unrestricted use, distribution, and reproduction in any medium, provided you give appropriate credit to the original author(s) and the source, provide a link to the Creative Commons license, and indicate if changes were made.

\section{References}

1. Bernal P, Lemaire S, Pinho MG, Mobashery S, Hinds J, Taylor PW (2010) Insertion of epicatechin gallate into the cytoplasmic membrane of methicillin-resistant Staphylococcus aureus disrupts penicillin-binding protein (PBP) 2a-mediated-lactam resistance by delocalizing PBP2. J Biol Chem 285:24055-24065

2. Bisicchia P, Noone D, Lioliou E, Howell A, Quigley S, Jensen T et al (2007) The essential YycFG two-component system controls cell wall metabolism in Bacillus subtilis. Mol Microbiol 65:180-200

3. Cicerale S, Lucas LJ, Keast RS (2012) Antimicrobial, antioxidant and anti-inflammatory phenolic activities in extra virgin olive oil. Curr Opin Biotech 23:129-135

4. Clavel T, Carlin F, Lairon D, Nguyen-The C, Schmitt P (2004) Survival of Bacillus cereus spores and vegetative cells in acid media simulating human stomach. J Appl Microbiol 97:214-219

5. Cote J, Caillet S, Doyon G, Sylvain JF, Lacroix M (2010) Bioactive compounds in cranberries and their biological properties. Crit Rev Food Sci Nutri 50:666-679

6. Daglia M (2012) Polyphenols as antimicrobial agents. Curr Opin Biotech 23:174-181

7. Ebisawa R, Tamura T, Ozawa M, Mura K (2015) Comparison of the antioxidant activities between the proanthocyanidin of a different degree of polymerization from peanut skin. Food Preserv Sci 41:3-8

8. Engels C, Schieber A, Ganzle MG (2011) Inhibitory spectra and modes of antimicrobial action of gallotannins from mango kernels (Mangifera indica L.). Appl Env Microbiol 77:2215-2223

9. Friedman M (2007) Overview of antibacterial, antitoxin, antiviral, and antifungal activities of tea flavonoids and teas. Mol Nutri Food Res 51:116-134
10. Friedman M, Henika PR, Levin CE, Mandrell RE, Kozukue N (2006) Antimicrobial activities of tea catechins and theaflavins and tea extracts against Bacillus cereus. J Food Prot 69:354-361

11. Granese T, Cardinale F, Cozzolino A, Pepe S, Ombra M, Nazzaro $F$ et al (2014) Variation of polyphenols, anthocyanins and antioxidant power in the strawberry grape (Vitis labrusca) after simulated gastro-intestinal transit and evaluation of in vitro antimicrobial activity. Food Nutri Sci 5:60-65

12. Ha JH, Ha SD (2011) Synergistic effects of sodium hypochlorite and ultraviolet radiation in reducing the levels of selected foodborne pathogenic bacteria. Foodborne Pathog and Dis 8:587-591

13. Jordan S, Hutchings MI, Mascher T (2008) Cell envelope stress response in Gram-positive bacteria. FEMS Microbiol Rev 32:107-146

14. Nanamiya H, Kasai K, Nozawa A, Yun CS, Narisawa T, Murakami K et al (2008) Identification and functional analysis of novel (p)ppGpp synthetase genes in Bacillus subtilis. Mol Microbiol 67:291-304

15. Poole K (2012) Bacterial stress responses as determinants of antimicrobial resistance. J Antimicrob Chemoth 67:2069-2089

16. Rao PV, Gan SH (2014) Cinnamon: a multifaceted medicinal plant. Evidence-based Complementary and Alternative Medicine: 642942

17. Singleton VL, Rossi JA (1965) Colorimetry of total phenolics with phosphomolybdic-phosphotungstic acid reagents. Americ Soc Enol Viticul 16:144-158

18. Tamura $\mathrm{T}$, Inoue $\mathrm{N}$, Ozawa $\mathrm{M}$, Shimizu-Ibuka A, Arai S, Abe N et al (2013) Peanut-skin polyphenols, procyanidin A1 and epicatechin- $(4 \beta \rightarrow 6)$-epicatechin- $(2 \beta \rightarrow \mathrm{O} \rightarrow 7,4 \beta \rightarrow 8)$-catechin, exert cholesterol micelle-degrading activity in vitro. Biosci Biotech Biochem 77:1306-1309

19. Tamura T, Kamei A, Ueda R, Arai S, Mura K (2014) Quality of imbibed soybean at an early stage of pregermination for development of a new protein food item. Biosci Biotech Biochem 78:115-123

20. Tamura T, Ozawa M, Kobayashi S, Watanabe H, Arai S, Mura K (2015) Inhibitory effect of oligomeric polyphenols from peanutskin on sugar digestion enzymes and glucose transport. Food Sci Technol Res 21:111-115

21. Tomochika K, Shimizu-Ibuka A, Tamura T, Mura K, Abe N, Onose $\mathrm{J}$ et al (2011) Effects of peanut-skin procyanidin A1 on degranulation of RBL-2H3 cells. Biosci Biotech Biochem 75:1644-1648

22. Verstraeten SV, Hammerstone JF, Keen CL, Fraga CG, Oteiza PI (2005) Antioxidant and membrane effects of procyanidin dimers and trimers isolated from peanut and cocoa. J Agric Food Chem 53:5041-5048

23. Wilson MK, Abergel RJ, Raymond KN, Arceneaux JE, Byers BR (2006) Siderophores of Bacillus anthracis, Bacillus cereus, and Bacillus thuringiensis. BBRC 348:320-325

24. Wu J, Xie J (2009) Magic spot: (p) ppGpp. J Cell Physiol 220:297-302 